\title{
Структурні та атрофічні зміни головного мозку у хворих на системний червоний вовчак
}

\section{С.О. Макаров}

Дніпровський державний медичний університет, Дніпро, Україна

\begin{abstract}
Анотація. Системний червоний вовчак (СЧВ) - хронічне захворювання аутоімунно-запального генезу, перебіг якого супроводжується залученням у патологічний процес майже всіх систем організму. Одним із типових проявів $\epsilon$ нейропсихіатричний СчВ - комплекс неврологічних і психічних розладів, що виникають у рамках цього захворювання. Мета: вивчити характеристики морфологічних порушень головного мозку у пацієнтів із СЧВ. Об'єкт і методи дослідження. Об'єктом дослідження були радіологічні зміни, зокрема атрофічні явища, головного мозку у хворих на СЧВ. Усім пацієнтам проводили нейровізуалізаційне обстеження - магнітно-резонансну томографію (МРТ) головного мозку на томографі з індукцією поля 1,5 Тл. Обстеження включало візуальну якісну оцінку томограм з метою виявлення структурних аномалій. Для оцінки атрофічних явищ розраховували морфометричні індекси, що являють собою відносні величини об'єму паренхіми головного мозку в тій чи іншій ділянці, - міжпівкульний індекс, індекс Сільвієвої борозни, міжфронтальний, міжкаудальний індекси. Результати. При проведенні МРТ лише в 1 пацієнта 2-ї групи виявлені зміни, а саме розширення лікворних просторів, тоді як ці порушення відмічені у 34 (62,9\%) пацієнтів основної групи (p=0,002). Також у 7 (12,9\%) хворих 1-ї групи виявлені післяінсультні кісти, у 25 (46,3\%) - лейкоареоз ( $(\mathrm{p}=0,006)$, у 8 (14,8\%) - демієлінізуючі процеси. Середні рівні морфометричних індексів атрофії головного мозку у обстежених хворих на СКВ коливалися від 0,055 (0,034; 0,061) — FFR до 0,304 (0,282; 0,318) - BFR. 3а усіма індексами атрофії головного мозку визначені статистично значущі розбіжності між групами дослідження зі статистично суттєво вищими ( $>$ <0,001) середніми показниками у хворих 1-ї групи, порівняно 2-ю. Висновки. У структурі морфологічних змін, що виявляються на МРТ головного мозку у хворих на СКВ, домінують неспецифічні зміни: атрофічні явища, лейкоареоз та розширення лікворних просторів. Поширеність радіологічних змін на МРТ головного мозку у пацієнтів із СЧВ з неврологічними проявами достовірно вища, ніж у пацієнтів із СЧВ без неврологічних проявів. Ступінь вираженості кіркової та підкіркової атрофії у пацієнтів із нейропсихіатричним СЧВ $\epsilon$ достовірно вищим, ніж у пацієнтів без неврологічних проявів, за всіма морфометричними індексами.
\end{abstract}

Ключові слова: системний червоний вовчак, неврологічні прояви, атрофія головного мозку, магнітно-резонансна томографія, морфометричні індекси.

\section{Вступ}

Системний червоний вовчак (СЧВ) являє собою хронічне запальне аутоімунне захворювання з мультисистемним характером ураження, що відмічається переважно у жінок молодого віку [1, 2]. Клінічні прояви СЧВ характеризуються широким різноманіттям симптомів, лабораторних і візуалізаційних змін. Однією з маніфестацій, що $є$ доволі типовою для цієї хвороби, $\epsilon$ нейропсихіатричний СЧВ (НСЧВ) - сукупність неврологічних і психічних порушень, що налічує 19 клінічних синдромів [3]. Проте слід зазначити, що єдиного погляду на класифікацію неврологічних проявів СЧВ наразі немає, і це залишається дискутабельним питанням [4].

Структурні порушення головного мозку (ГМ) $є$ досить типовими для пацієнтів із СЧВ як із неврологічними проявами, так i без них. Магнітно-резонансна томографія (МРТ) на сьогодні $\epsilon$ переважним методом у якості візуалізації структур нервової системи [5]. Проте слід зазначити, що у досить великої кількості пацієнтів (25-60\%) МРТ ГМ не дає змоги виявити жодної аномалії [6, 7]. Патогенетичні механізми виникнення радіологічних аномалій органів центральної нервової системи залишаються не повністю 3'ясованими. Найчастішими змінами на МРТ ГМ $\epsilon$ гіперінтенсивні вогнища у білій речовині ГМ (30-75\%) та атрофія ГМ (15-20\%) [8]. Зазначимо, що ці зміни не $\epsilon$ специфічними саме для НСЧВ, що опосередковано свідчить про множинність і гетерогенність патогенетичних механізмів їх формування [9-11].

Мета дослідження: вивчити характеристики морфологічних порушень ГМ у пацієнтів із СЧВ.

\section{Об'єкт і методи дослідження}

Об'єктом дослідження були радіологічні зміни, зокрема атрофічні явища, ГМ у хворих на СЧВ. Усім пацієнтам проводили нейровізуалізаційне обстеження - МРТ ГМ на томографі з індукцією поля 1,5 Тл. Обстеження включало візуальну якісну оцінку томограм з метою виявлення структурних аномалій. Для оцінки атрофічних явищ розраховували наступні морфометричні індекси, що являють собою відносні величини об'єму паренхіми ГМ в тій чи іншій ділянці [12]:

1. Міжпівкульний індекс (frontal interhemispheric fissure ratio FFR) - розраховують шляхом ділення найбільшого значення ширини міжпівкульної борозни на транс-пінеальний внутрішньочерепний діаметр. Для цього можна використовувати будь-яке зображення, що демонструє лобові частки ГМ.

2. Індекс Сільвієвої борозни (Sylvian fissure ratio - SFR) обчислюють шляхом ділення середнього значення найбільшої ширини Сільвієвої борозни на транс-пінеальний внутрішньочерепний діаметр. Для цього використовують зображення, що демонструє найбільш широку Сільвієву борозну.

3. Міжфронтальний індекс (bifrontal ratio - BFR) - обчислюють шляхом ділення відстані між верхівками передніх рогів бічних шлуночків на внутрішній діаметр черепа, що проходить на тому самому рівні.

4. Міжкаудальний індекс (bicaudate ratio - BCR) - вимірюють шляхом ділення відстані між бічними шлуночками (їх передніми рогами) на рівні голівок хвостатих ядер на внутрішній діаметр черепа на тому самому рівні.

Перші два індекси (FRR та SFR) використовували для визначення ступеня кіркової атрофії, останні два (BFR та BCR) - для визначення ступеня підкіркової атрофії.

Проведено комплексне обстеження 64 хворих на СЧВ, що проходили лікування у відділенні ревматології та відділенні нефрології комунального підприємства «Дніпропетровська обласна клінічна лікарня ім. І.І. Мечникова» Дніпропетровської обласної ради» протягом 2018-2021рр., яке включало повне клініко-неврологічне обстеження, нейропсихологічне тестування, лабораторне та нейровізуалізаційне дослідження. Серед обстежуваних 85,9\% (n=55) - жінки, 14,1\% (n=9) - чоловіки. Середній вік хворих - 44 роки, середній вік встановлення діагнозу $-29,75 \pm 9,03$ року. 
Неврологічні прояви виявлені у 54 (84,4\%) пацієнтів (1-ша група, основна), у 10 (15,6\%) осіб неврологічних проявів не виявлено (2-га група, контрольна).

\section{Результати}

При проведенні МРТ лише у 1 пацієнта 2-ї групи виявлено зміні, а саме розширення лікворних просторів, тоді як ці порушення відмічено у $34(62,9 \%)$ пацієнтів основної групи $(p=0,002)$. Також у 7 (12,9\%) пацієнтів 1-ї групи виявлено післяінсультні кісти, у $25(46,3 \%)$ - лейкоареоз ( $p=0,006)$, у $8(14,8 \%)$ - демієлінізуючі процеси (рис. 1).

Рисунок 1 Частка хворих із виявленими на MPT/комп'ютерній томографії ознаками порушень ГМ (у \% на 100 обстежених)

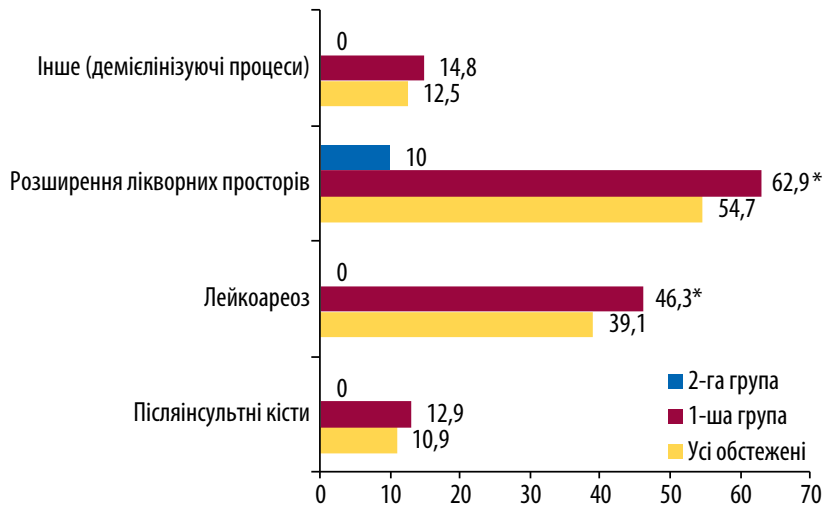

${ }^{*}$ p $<0,01$ за критерієм $\chi^{2}$ Пірсона порівняно 3 2-ю групою.

Середні рівні морфометричних індексів атрофії ГМ у обстежених хворих на СЧВ коливалися від 0,055 $(0,034 ; 0,061)-F F R$ до $0,304(0,282 ; 0,318)$ - BFR (таблиця).

Таблиця Оцінка середнього рівня морфометричних індексів атрофії ГМ у обстежених хворих на СЧВ (Ме (25\%; 75\%))

\begin{tabular}{ccccc}
\hline Індекс & $\begin{array}{c}\text { Усі обстежені, } \\
\mathrm{n}=64\end{array}$ & $\begin{array}{c}\text { 1-ша група, } \\
\mathrm{n}=54\end{array}$ & $\begin{array}{c}\text { 2-га група, } \\
\mathbf{n}=10\end{array}$ & $\mathbf{p}$
\end{tabular}

BCR, Me $(25 \% ; 75 \%) \quad 0,139(0,124 ; 0,157) \quad 0,148(0,128 ; 0,158) \quad 0,074(0,06 ; 0,126)<0,001$ BFR, Me $(25 \% ; 75 \%) \quad 0,304(0,282 ; 0,318) \quad 0,312(0,298 ; 0,322) \quad 0,212(0,202 ; 0,282)<0,001$ FFR, Me $(25 \% ; 75 \%) \quad 0,055(0,034 ; 0,061) \quad 0,058(0,048 ; 0,062) \quad 0,032(0,029 ; 0,036)<0,001$ SFR, Me $(25 \% ; 75 \%) \quad 0,057(0,036 ; 0,061) \quad 0,058(0,046 ; 0,062) \quad 0,034(0,031 ; 0,038)<0,001$ p — розбіжності між групами за критерієм Манна — Уітні (U).

За усіма індексами атрофії ГМ визначені статистично значущі розбіжності між групами дослідження зі статистично суттєво вищими $(p<0,001)$ середніми показниками у хворих 1-ї групи порівняно 2-ю (рис. 2).

Рисунок 2 Оцінка середнього рівня індексів атрофії ГМу обстежених хворих на СЧВ у групах дослідження (середні бали - медіана, інтерквартильний розмах та мінімальне і максимальне значення)

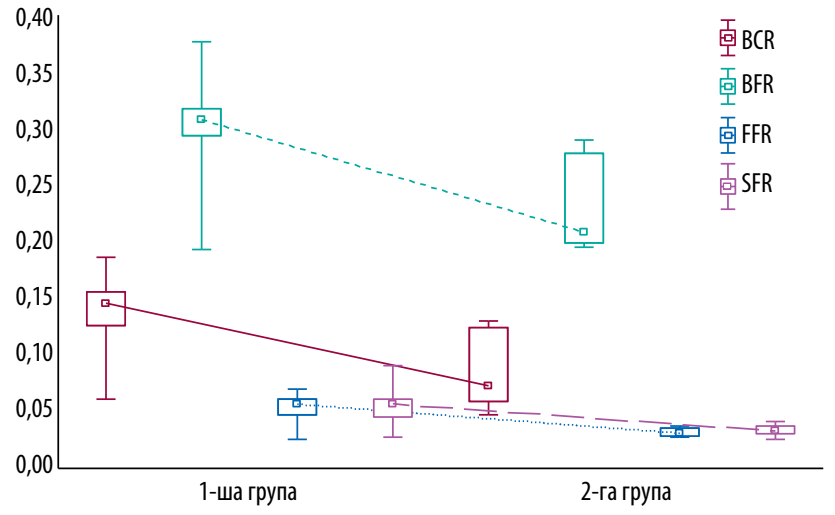

Індекси атрофії ГМ корелювали між собою та з виявленими на MPT/комп'ютерній томографії ознаками порушень ГМ, найпотужніші зв'язки виявлено між індексами атрофії FFR та SFR $\left(r_{s}=0,93 ; p<0,001\right), B C R$ та BFR $\left(r_{s}=0,83 ; p<0,001\right), B F R$ та FFR $\left(r_{s}=0,74\right.$; $p<0,001), B F R$ та SFR $\left(r_{s}=0,69 ; p<0,001\right)$; між індексами атрофії та органічними порушеннями: між BFR та розширенням лікворних просторів $\left(r_{s}=0,52 ; p<0,001\right)$, між FFR та розширенням лікворних просторів $\left(r_{s}=0,49 ; p<0,001\right)$, між SFR та лейкоареозом $\left(r_{s}=0,52\right.$; $\mathrm{p}<0,001)$

\section{Обговорення}

Морфологічні зміни ГМ $\epsilon$ типовими у пацієнтів із СЧВ, особливо у тієї частки хворих, які мають так звані нейропсихіатричні прояви. На жаль, дотепер не існує будь-якого специфічного радіологічного маркера, характерного саме для НСЧВ: найчастішими змінами у обстеженої когорти хворих були розширення лікворних просторів, поява гіперінтенсивних вогнищ у білій речовині ГМ, що традиційно описується терміном «лейкоареоз», «вогнища судинного генезу» та атрофічні зміни ГМ. Більш рідкісним було виявлення післяінсультних кіст та демієлінізуючого процесу ГМ. Ступінь вираженості атрофічних явищ оцінювали за допомогою вимірювання індексів кіркової та підкіркової атрофії. Базуючись на значенні цих показників, встановлено статистично значущі відмінності між ступенем вираженості атрофічних явищ у пацієнтів основної групи (1-ї) і групи контролю (2-ї), тобто серед пацієнтів 1-ї групи ці показники були вищими.

\section{Висновки}

1. У структурі морфологічних змін, що виявляються на МРТ ГМ у хворих на СЧВ, домінують неспецифічні зміни: атрофічні явища, лейкоареоз та розширення лікворних просторів.

2. Поширеність радіологічних змін на МРТ ГМ у пацієнтів із СЧВ з неврологічними проявами достовірно вища, ніж у паці$\epsilon$ ттів із СЧВ без неврологічних проявів.

3. Ступінь вираженості кіркової та підкіркової атрофії у паці$\epsilon$ нтів із НСЧВ $\epsilon$ достовірно вищим, ніж у пацієнтів без неврологічних проявів, за всіма морфометричними індексами.

\section{Перспективи подальших досліджень}

Перспективним $\epsilon$ вивчення факторів, які впливають на виникнення морфологічних змін ГМ у пацієнтів із НСЧВ, вивчення взаємозв'язку між структурними змінами ГМ та клінічними проявами, лабораторними особливостями та розробка моделі прогнозування появи цих змін.

\section{Конфлікт інтересів}

Конфлікту інтересів немає.

\section{Назва та номер державної реєстрації наукової теми}

Робота $\epsilon$ фрагментом виконання теми науково-дослідної роботи кафедри неврології державного закладу «Дніпропетровська медична академія МОЗ України» «Порушення нервової системи при пароксизмальних, нейроімунологічних та цереброваскулярних захворюваннях», № державної реєстрації 01190000001.

Робота виконана в рамках дисертаційної роботи «Особливості порушень нервової системи та їх аутоімунні маркери у хворих на системний червоний вовчак».

\section{Список використаної літератури}

1. Makarov S.0. (2018) Nervous system impairment under systemic lupus erythematosus: pathogenesis aspects, prevalence and viewson clinical manifestations classification. Ukr. Neurol. J., 2: 25-29. D0I: 10.30978/UNZ2018225.

2. Fava A., Petri M. (2019) Systemic lupus erythematosus: diagnosis and clinical management. J. Autoimmun., 96: 1-13. D0I: 10.1016/j.jaut.2018.11.001.

3. Liang M.H., Corzillius M., Bae S.C. et al. (1999) The American College of Rheumatology nomenclature and case definitions for neuropsychiatric lupus syndromes. Arthritis rheum., 42(4): 599-608.

4. Makarov S.0. (2021) Structure of neurological manifestations in patients with systemic lupus erythematosus. Bull. Probl. Biol. Med., 159(2): 90-93. D01:10.29254/2077-4214-2021-1159-90-93. 
5. Bertsias G.K., Ioannidis J.P.A., Aringer M. et al. (2010) EULAR recommendations for the management of systemic lupus erythematosus with neuropsychiatric manifestations: report of a task force of the EULAR standing committee for clinical affairs. Ann. Rheum. Dis., 69(12): 2074-2082. DOl: 10.1136/ard.2007.070367.

6. Csépány T., Bereczki D., Kollár J. et al. (2003) MRI findings in central nervous system systemic lupus erythematosus are associated with immunoserological parameters and hypertension. J. Neurol., 250(11): 1348-1354. D0l: 10.1007/s00415-003-0223-0.

7. Toledano P., Sarbu N., Espinosa G. et al. (2013) Neuropsychiatric systemic lupus erythematosus: magnetic resonance imaging findings and correlation with clinical and immunological features. Autoimmun. Rev., 12(12): 1166-1170. D0l: 10.1016/j.autrev.2013.07.004.

8. Sarbu N., Bargalló N., Cervera R. (2015) Advanced and conventional magnetic resonance imaging in neuropsychiatric lupus. F1000Res., 4: 162.

9. Sarbu N., Alobeidi F., Toledano P. et al. (2015) Brain abnormalities in newly diagnosed neuropsychiatric lupus: systematic MRl approach and correlation with clinical and laboratory data in alargemulticenter cohort.Autoimmun. Rev., 14(2): 153-159.D0l:10.1016/j.autrev.2014.11.001.

10. Steup-Beekman G.M., Zirkzee E.J., Cohen D. et al. (2013) Neuropsychiatric manifestations in patients with systemic lupus erythematosus: epidemiology and radiology pointing to an immune-mediated cause. Ann. Rheum. Dis., 72 (Suppl. 2):ii76-ii79. D0l: 10.1136/annrheumdis-2012-202369.

11. Luyendijk J., Steens S.C.A., Ouwendijk W.J.N. et al. (2011) Neuropsychiatric systemic lupus erythematosus: lessons learned from magnetic resonance imaging. Arthritis Rheum., 63(3): 722-732. DOI: 10.1002/art.30157.

12. Gomori J.M., Steiner I., Melamed E., Cooper G. (1984) The assessment of changes in brain volume using combined linear measurements. Neuroradiology, 26(1):21-24. D0I: 10.1007/ BF00328197.

\section{Structural and atrophic changes in the brain in patients with systemic lupus erythematosus}

\section{S.O. Makarov}

Dnipro State Medical University, Dnipro, Ukraine

Abstract. Systemic lupus erythematosus (SLE) is a chronic disease of autoimmune-inflammatory origin occurring with the involvement of

Відомості про автора:
Макаров Сергій Олександрович — асистент кафедри неврології Дніпровського державно-
го медичного університету, Дніпро, Україна.
Адреса для кореспонденції:
Макаров Сергій Олександрович
49044, Дніпро, вул. Володимира Вернадського, 9
E-mail: makarov295062@gmail.com

\section{Відомості про автора:}

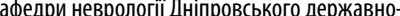

Макаров Сергій Олександрович

E-mail:makarov295062@gmail.com many organ systems. One of the typical manifestations is neuropsychiatric SLE - a complex of neurological and mental disorders that arise in patients with this disease. Aim: to study the characteristics of morphological disorders of the brain in patients with SLE. Object and research methods. The object of the study was radiological findings, in particular atrophic phenomena, of the brain in patients with SLE. All patients underwent neuroimaging examinations - magnetic resonance imaging (MRI) of the brain on an apparatus with a field induction of 1.5 T. This examination included a visual qualitative assessment of tomograms in order to identify structural abnormalities. To assess atrophic phenomena, the morphometric indices were calculated, which represent the relative values of the volume of the brain parenchyma in a particular area, - FFR, SFR, BFR and BCR. Results. During MRI, only one patient in group 2 was found to have changes, namely the expansion of cerebrospinal fluid spaces, while in 34 (62.9\%) patients of the main group, these disorders were identified $(p=0.002)$. Also in $7(12.9 \%)$ patients in group 1, post-stroke cysts were found, leukoaraiosis ( $p=0.006)$ in $25(46.3 \%)$, and demyelinating processes in 8 (14.8\%). Average levels of morphometric indices of brain atrophy in examined patients with SLE ranged from 0.055 (0.034; $0.061)$ - FFR to $0.304(0.282 ; 0.318)$ - BFR. For all indices of brain atrophy, statistically significant differences between the study groups were determined according to statistically significantly higher $(p<0.001)$ mean values in patients of group 1, compared to group 2 . Conclusions. In the structure of morphological changes detected on MRI of the brain in patients with SLE, nonspecific findings dominate: atrophic phenomena, leukoaraiosis and expansion of cerebrospinal fluid spaces. The prevalence of radiological findings on MRI of the brain in patients with SLE with neurological manifestations is significantly higher than in patients with SLE without neurological manifestations. The severity of cortex and subcortical atrophy in patients with neuropsychiatric SLE is significantly higher than in patients without neurological manifestations in all morphometric indices.

Key words: systemic lupus erythematosus, neurological manifestations, brain atrophy, magnetic resonance imaging, morphometric indices.

\section{Information about the author:}

Makarov Serhii 0. - Assistant Professor of Department of Neurology of the Dnipro State Medical University, Dnipro, Ukraine.

Address for correspondence:

Serhii Makarov

49044, Dnipro, Volodymyr Vernadsky str., 9

E-mail: makarov295062@gmail.com 